University of South Florida

DIGITAL COMMONS

Digital Commons @ University of

@ UNIVERSITY OF SOUTH FLORIDA

South Florida

1999

\title{
Variations in Global Mean Sea Level Associated with the 1997-1998 ENSO Event: Implications for Measuring Long Term Sea Level Change
}

\author{
R. S. Nerem \\ The University of Texas at Austin \\ D. P. Chambers \\ The University of Texas at Austin, donc@usf.edu \\ E. W. Leuliette \\ The University of Texas at Austin \\ Gary T. Mitchum \\ University of South Florida, mitchum@usf.edu \\ B. S. Giese \\ Texas A\&M University
}

Follow this and additional works at: https://digitalcommons.usf.edu/msc_facpub

Part of the Life Sciences Commons

\section{Scholar Commons Citation}

Nerem, R. S.; Chambers, D. P.; Leuliette, E. W.; Mitchum, Gary T.; and Giese, B. S., "Variations in Global Mean Sea Level Associated with the 1997-1998 ENSO Event: Implications for Measuring Long Term Sea Level Change" (1999). Marine Science Faculty Publications. 1433.

https://digitalcommons.usf.edu/msc_facpub/1433

This Article is brought to you for free and open access by the College of Marine Science at Digital Commons @ University of South Florida. It has been accepted for inclusion in Marine Science Faculty Publications by an authorized administrator of Digital Commons @ University of South Florida. For more information, please contact digitalcommons@usf.edu. 


\title{
Variations in global mean sea level associated with the 1997- 1998 ENSO event: Implications for measuring long term sea level change
}

\author{
R. S. Nerem, D. P. Chambers, E. W. Leuliette \\ Center for Space Research, The University of Texas at Austin
}

\section{G. T. Mitchum}

Department of Marine Science, University of South Florida

\section{B. S. Giese}

Department of Oceanography, Texas A\&M University

\begin{abstract}
The TOPEX/POSEIDON satellite has observed variations in global mean sea level with a precision of $4 \mathrm{~mm}$ at 10-day intervals since late 1992. During the 1997-1998 ENSO event, a $20 \mathrm{~mm}$ rise, and subsequent fall, of mean sea level was observed. These changes are well correlated with global mean sea surface temperature anomalies, which exhibit a similar response for every major ENSO event since 1981 , suggesting the observed mean sea level change is mostly caused by thermal expansion. An Empirical Orthogonal Function analysis of the altimeter-derived sea level maps also suggests a connection with ENSO. We observed the same signal in global mean dynamic heights of the MOM2 ocean model and in anomalies of global mean precipitable water vapor. The presence of ENSO-variability in global mean sea level suggests that detecting the much smaller sea level variations associated with climate change will require at least a decade of precise altimeter measurements.
\end{abstract}

\section{Introduction}

Variations in mean sea level are an important indicator for a variety of phenomena affecting the coupled Earth system, including climate change, but they also have a number of social and economic consequences. The TOPEX/POSEIDON (T/P) satellite has observed "global" $\left( \pm 66^{\circ}\right.$ latitude) variations in mean sea level since late 1992 from an orbit that repeats every 10 days [Fu et al., 1994] and has a $300 \mathrm{~km}$ spacing at the equator. Prior analyses of these observations have been reported by Nerem [1995a; 1995b], and Minster et al. [1995; 1999]. These studies established that the precision of the 10-day global mean sea level estimates is approximately $4 \mathrm{~mm}$, more than sufficient for climate change studies. The accuracy of these estimates has been more difficult to determine, although steady progress has been made over the last few years, mainly through comparisons to sea level measurements made at tide gauges [e.g. Mitchum, 1994]. The tide gauges successfully detected an error in the sign of the oscillator correction being applied to the TOPEX data [Mitchum, 1998]. A drift in the TOPEX Microwave Radiometer (TMR) which supplies the wet troposphere correction [Haines and Bar-Sever, 1998] has also been detected using the tide gauges [Chambers et al., 1998; Mitchum, 1998].

\section{Copyright 1999 by the American Geophysical Union.}

Paper number 1999GL002311.

0094-8276/99/1999GL002311\$05.00

\section{Altimeter Data Analysis}

T/P carries two altimeters; a dual-frequency altimeter (TOPEX) and a single-frequency altimeter (POSEIDON) which operate on a $90 \% / 10 \%$ duty schedule. For this study, we employed TOPEX and POSEIDON data (Merged Geophysical Data Records Revision B) from Cycles 10-233, which covers the time period 1993-1998. All of the usual corrections have been applied to the data [Nerem, 1995b], including the oscillator and internal calibration estimates [Hayne et al., 1994; Nerem, 1997], with the exception that no correction was applied for the inverted barometer effect [Nerem, 1995b]. In addition, we applied a correction [Keihm et al., 1998] for a known drift in the TMR measurements, which results in an increase in mean sea level rise of $1.2 \mathrm{~mm} /$ year [Haines and Bar-Sever, 1998] after the correction is applied. Finally, we applied the cycle-by-cycle TOPEX-tide gauge calibration estimates of Mitchum [1998] directly to the raw altimeter data, except that we removed seasonal variations from this correction. No correction was applied to the POSEIDON data, but there are only 21 POSEIDON cycles, so this data had little impact on the results of this study.

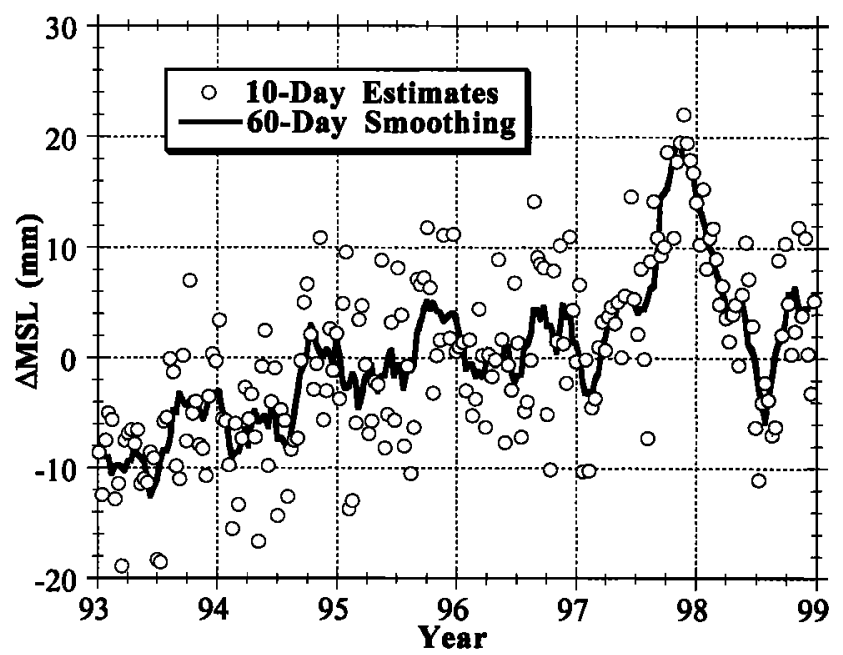

Figure 1. Variations in global mean sea level computed from TOPEX/POSEIDON cycles 10-233, after applying the tide gauge calibration. Each open circle is a single 10-day estimate of global mean sea level. The solid line represents smoothing of these 10-day estimates using a 60-day boxcar filter. The rate of sea level rise over the entire record is $2.6 \mathrm{~mm} /$ year. 
SSH 1 (27.28\%) $0.60 \mathrm{~mm} / \mathrm{yr}$

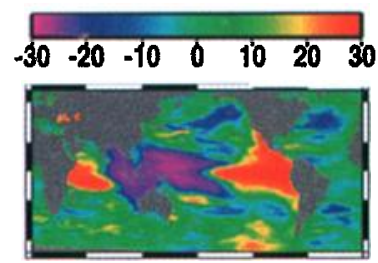

SST $1(18.33 \%) 0.021^{\circ} \mathrm{C} / y r$

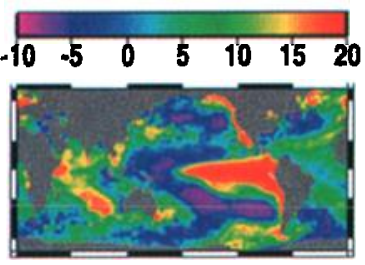

SSH $2(11.83 \%) 1.81 \mathrm{~mm} / \mathrm{yr}$

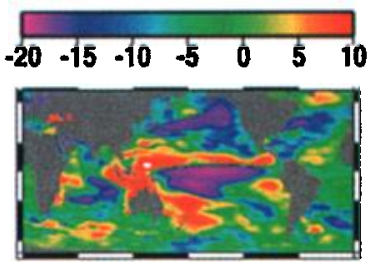

SST $2(11.58 \%) 0.038^{\circ} \mathrm{C} / y r$

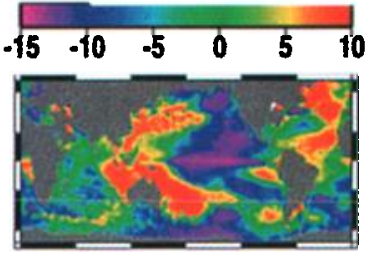

SSH $3(8.44 \%) 0.81 \mathrm{~mm} / \mathrm{yr}$

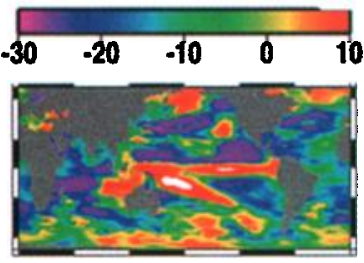

SST $3(7.78 \%) 0.004^{\circ} \mathrm{C} / \mathrm{yr}$
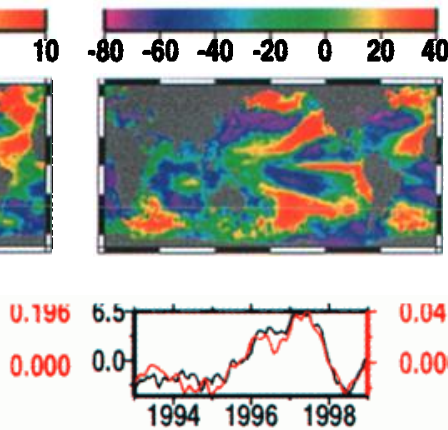

0.041 $\sin 4(3.87 \%) 0.04 \mathrm{~mm} / \mathrm{y}$

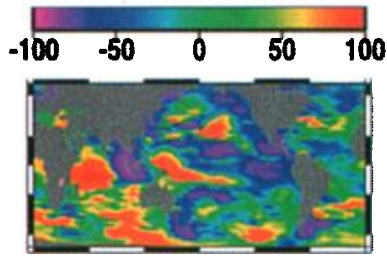

SST $5(3.88 \%) 0.000^{\circ} \mathrm{C} / y r$
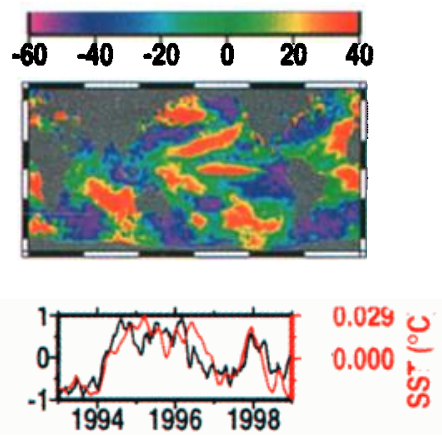

$\begin{array}{lll}1994 & 1996 & 1998\end{array}$
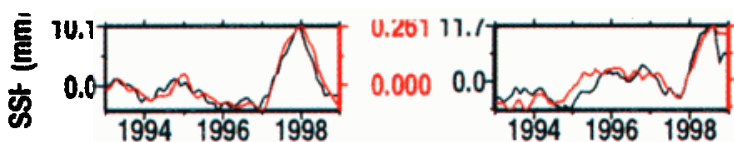

Figure 2. The first 4 leading modes of an EOF decomposition of the 10-day sea level maps produced from T/P data, and sea surface temperature (SST Mode 5 is shown in place of Mode 4 because it correlates better with sea level). Annual and semi-annual variations have been removed before computing the EOFs, and the temporal modes have been smoothed using a 60-day boxcar filter. The EOF modes have been scaled by their global mean, so that their contribution to the global mean sea level variation can be ascertained.

Global mean sea level was computed from this corrected data set using a simple equi-area weighted average [Nerem, 1995b]. The resulting 10-day estimates are shown in Figure 1. Errors in the ocean tide correction, the ionosphere correction, and other quantities that vary with the Earth's rotation, tend to alias to near a 60-day period in mean sea level, thus we have reduced these errors by smoothing the 10-day estimates using a 60-day boxcar filter. Figure 1 shows a $20 \mathrm{~mm}$ rise and subsequent fall of mean sea level over 1997-1998 which roughly coincides with the 1997-1998 ENSO event. The observed rate of sea level rise over 1993-1998 is $2.6 \mathrm{~mm} / \mathrm{year}$.

In order to help diagnose the cause of the observed sea level change, we decomposed a time series of T/P sea level

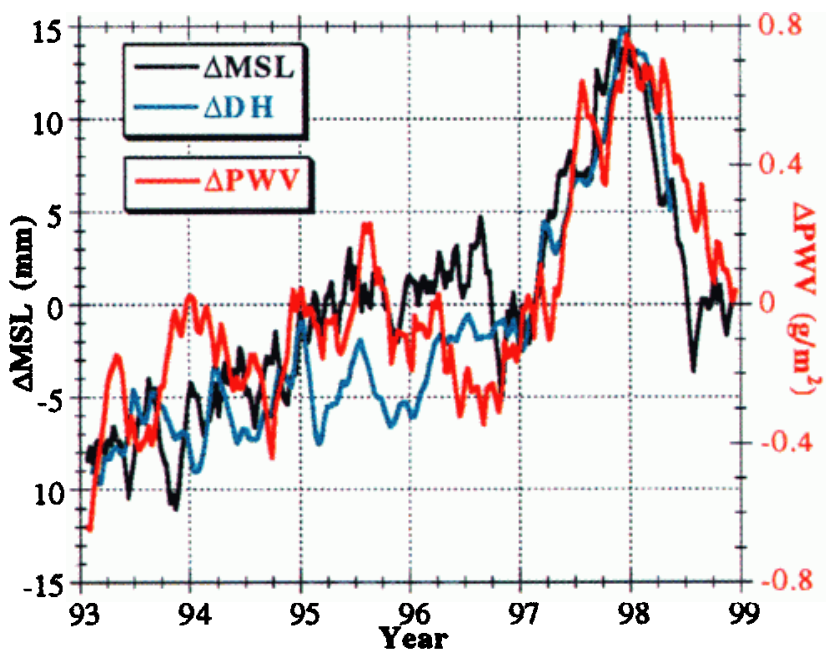

Figure 3. Comparison of variations of global mean sea level from T/P (black), global mean dynamic height from the MOM2 model (surface to $1000 \mathrm{~m}$, blue), and global mean precipitable water vapor (red) from the TOPEX Microwave Radiometer (TMR). Annual and semi-annual variations have been removed from each, and the results smoothed with a 60-day boxcar filter. maps [Tapley et al., 1994] using the technique of Empirical Orthogonal Functions (EOFs) [Hendricks et al., 1996]. We applied an inverted barometer correction to these maps to reduce contamination of the EOF modes. Figure 2 shows the leading EOF modes from this analysis for both sea level and sea surface temperature, the latter of which will be discussed later. These EOFs have been scaled to represent their contribution to the global mean. Note that the first three "ENSO modes" describe most of the 1997-1998 ENSO event in global mean sea level. Mode 1 began rising at the beginning of 1997 , peaked in early 1998 at $10 \mathrm{~mm}$, and then fell back to zero by the end of 1998 . Mode 2 began rising at the beginning of 1998, peaking at $12 \mathrm{~mm}$ in mid 1998. Mode 3 is similar to Mode 2, but smaller in amplitude. All of these modes show large signals in the tropics, as expected, but also

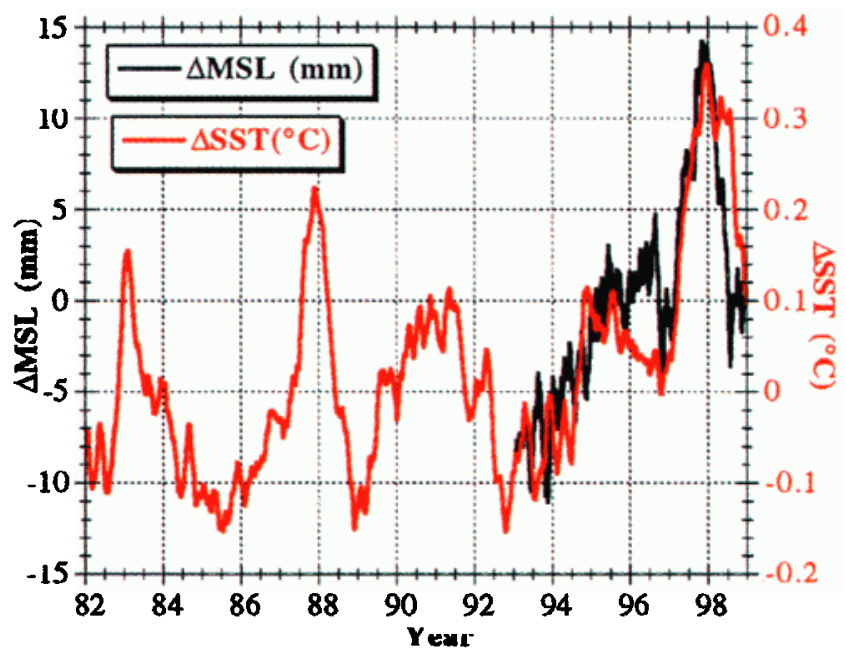

Figure 4. A comparison of global mean sea level from $T / P$ (black) and satellite-observed global mean SST anomalies (red) from Reynolds and Smith [1994]. Annual and semiannual variations have been removed from each, and the results smoothed with a 60 -day boxcar filter. 
large extratropical signals, especially in the Southern Ocean. Peterson and White [1998] have seen similar ENSO-related extratropical signals in sea surface temperature, which they attribute to atmospheric coupling between the two regions.

We were interested to see if the change in global mean sea level during the ENSO event could be reproduced by a global numerical ocean model. We used an intermediate resolution version of the Modular Ocean Model 2 (MOM2) code developed at the National Oceanic and Atmospheric Administration's Geophysical Fluid Dynamics Laboratory [Pacanowski, 1995]. The model incorporates an optimal interpolation scheme [Carton et al., 1996] which assimilates ocean temperature profiles and is forced with weekly NCEP winds [Kalnay et al., 1996]. Sea surface temperature is damped to NCEP weekly values and the sea surface salinity is damped to monthly mean climatology from the comprehensive ocean atmosphere data set (COADS) [daSilva et al., 1994]. The damping time scale for both temperature and salinity is 50 days. The model was spun up from 1985 to 1991.

The model temperature and salinity fields were used to calculate dynamic height at several depths assuming a level of no motion of $1000 \mathrm{~m}$. Dynamic height at the surface should most closely resemble sea level height as observed by $T / P$, and in fact the two curves do closely match each other (Figure 3). Since T/P observations are not used in the assimilation, this confirms that the model and satellite are independently detecting a real oceanic signal. By comparing the mean dynamic heights for different reference depths, we found that most of the dynamic height variability associated with the ENSO event is confined to the upper few hundred meters. The total contribution to dynamic height from below $200 \mathrm{~m}$ is characterized by a small linear trend $(<0.5 \mathrm{~mm} /$ year $)$ from the beginning of the record, and does not show a distinct ENSO structure. The confinement of dynamic height anomalies to the upper ocean suggests a surface forcing instead of a dynamic forcing that would presumably be located near the thermocline, and therefore be deeper in the water column.

\section{Comparisons to Sea Surface Temperature and Precipitable Water Vapor}

We have computed global mean anomalies of sea surface temperature (SST) using the satellite-observed datasets of Reynolds and Smith [1994]. Figure 4 shows a comparison of mean variations of sea level and SST, where the small $(3 \mathrm{~mm})$ annual variations of global mean sea level have been removed to facilitate the comparison. The correlation of the two time

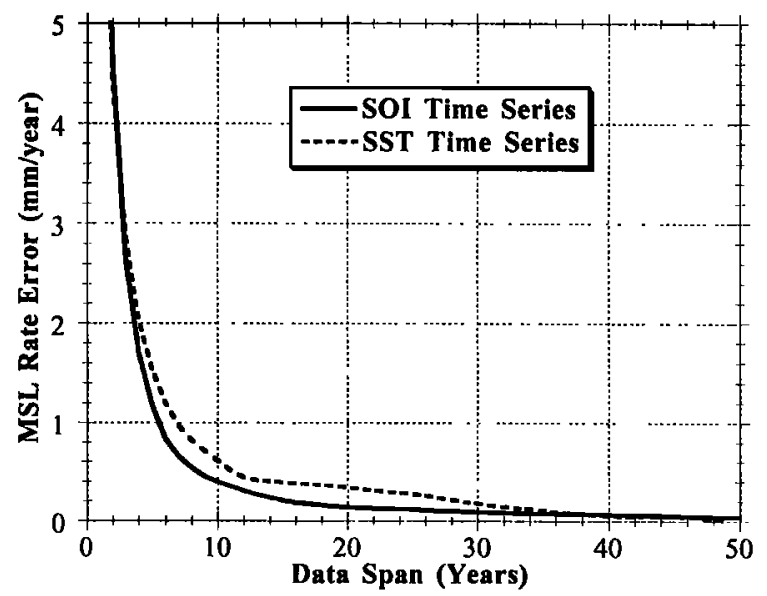

Figure 5. The accuracy of the rate of global mean sea level rise, determined from a Monte Carlo simulation using simulated global mean sea level time series constructed from SOI and SST observations, versus the length of the data span employed.

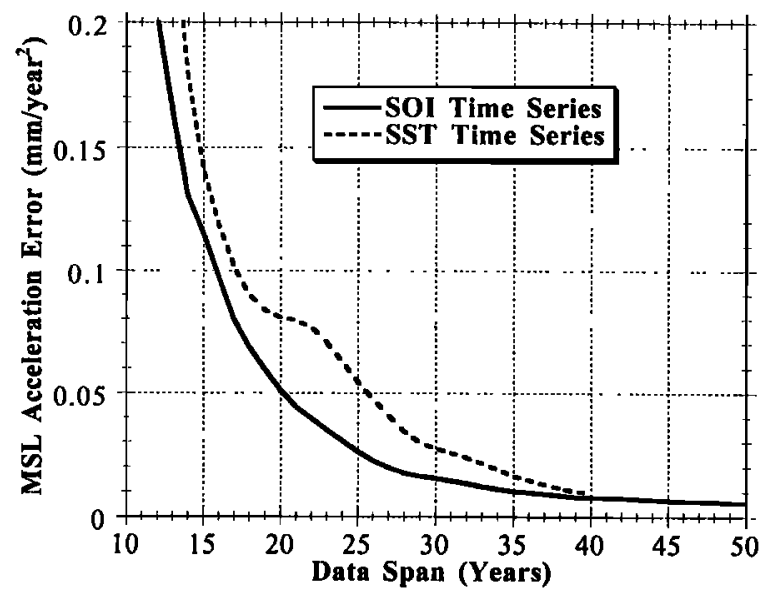

Figure 6. Same as Figure 5, but for the acceleration of global mean sea level.

series is quite evident, both during the recent ENSO event, where SST peaks at $+0.4^{\circ} \mathrm{C}$ (by far the largest global mean SST anomaly since 1981), as well as earlier in the record. Note that the rise of sea level and SST during the ENSO event is nearly coincident, but the fall in sea level leads the fall in SST by several months. This lag suggests that temperatures in the subsurface returned to normal before the surface temperatures. There are peaks in the global mean SST anomalies for every major ENSO event since 1981, again suggesting that the observed change in mean sea level is related to ENSO. While not shown here, averaging the SST anomalies into latitude bands shows that much of the observed increase during 1997 came from the $10^{\circ} \mathrm{S}-10^{\circ} \mathrm{N}$ latitude band, with little signal outside of the tropics. The change in SST during ENSO is symmetric with respect to the equator, whereas the corresponding change in sea level is anti-symmetric and biased towards the southern hemisphere. The leading modes of an EOF decomposition of the SST maps during the T/P mission are qualitatively quite similar to the corresponding sea level modes shown in Figure 2. The correlation of the fields suggest the application of canonical correlation analysis or coupled pattern analysis might be preferable for extracting the co-varying part of the two fields, however Leuliette and Wahr [1999] have shown this will provide comparable results to the standard EOF approach we have used here when seasonal terms are removed.

We have also computed global mean anomalies of precipitable water vapor (PWV) using measurements from the TOPEX Microwave Radiometer (TMR). These measurements have been calibrated using the aforementioned drift estimate. As shown in Figures 3 and 4, the correlation of global mean variations of sea level, SST, and PWV is quite high, although the spatial variations given by EOFs of the PWV maps (not shown) are noticeably different from sea level and SST (Figure 2 ). The correlation of the smoothed variations of SST and PWV peaks at 0.91 with zero lag. Coupled with evidence that Outgoing Longwave Radiation (OLR) decreased in a similar manner during the ENSO event [Jackson and Stephens, 1995; Wong et al., 1998], one possible mechanism for the observed sea level change is an increase in water vapor associated with ENSO, which in turn decreased the OLR causing the ocean to retain heat during ENSO. However, this is difficult to verify, as a global change in heat flux of only $7 \mathrm{~W} / \mathrm{m}^{2}$ is needed to change sea level by $20 \mathrm{~mm}$, but the observed fluxes are only accurate to $20 \mathrm{~W} / \mathrm{m}^{2}$.

\section{Implications for Detecting Climate Change}

Perhaps the most important result of this study is the implications of the results for studies of climate change using 
satellite altimetry. Although T/P has observed an increase in mean sea level of $2.6 \mathrm{~mm} /$ year over 1993-1998 (Figure 1), the presence of ENSO-scale variability in global mean sea level means that a longer time series will be needed to reduce this variability through averaging to reveal the smaller climate signals. To assess the impact of such variability, we developed two simulated long time series of global mean sea level variations, both containing ENSO variability. The first was a $\sim 100$ year long (1882-1998) time series of the Southern Oscillation Index (SOI) which we linearly regressed against T/P mean sea level over 1993-1998 to determine the proper regression coefficients. The regression coefficients were then used to scale the SOI and simulate a $\sim 100$ year long time series of global mean sea level. A similar technique was applied to a set of reconstructed global mean SST anomalies [Smith et al., 1996] covering 1950-1998. In addition, the rate and acceleration of each of these time series was set to zero.

Each of these time series was then used to perform two simulations. In the first simulation, a $2 \mathrm{~mm} /$ year secular sea level change was added to the time series, and a series of Monte Carlo solutions were performed to determine the error in the estimated sea level rate by a least squares solution using varying data spans with a random midpoint time. The result of these simulations is a plot of the accuracy of the sea level rise estimate versus the length of the data span of altimeter data employed (Figure 5). Both simulations (using SOI or SST simulated sea level) suggest 10 years of T/P class altimetry will be required to determine the rate of mean sea level change to an accuracy of $0.5 \mathrm{~mm} / \mathrm{year}$, assuming the ENSO variations cannot be removed by other means. This is comparable to or greater than the expected measurement errors. These simulations were repeated by adding an acceleration (here defined using a $0.5 a t^{2}$ convention) of mean sea level of $0.06 \mathrm{~mm} / \mathrm{year}^{2}$, and estimating both the rate and acceleration of sea level change. Figure 6 shows the error in the estimated acceleration as a function of data span. The SST results are invalid after about 20 years because the time series is of insufficient length to test longer data spans. However, the $\mathrm{SOI}$ results suggest $\sim 30$ years of $\mathrm{T} / \mathrm{P}$ class altimetry will be needed to detect an acceleration of mean sea level to an accuracy of $0.02 \mathrm{~mm} / \mathrm{year}^{2}$.

\section{Conclusions}

Sea level measurements from the T/P mission have been used to detect a $20 \mathrm{~mm}$ rise and fall of global mean sea level coinciding with the 1997-1998 ENSO event. We have reproduced this change using the MOM2 ocean model and have determined this signal is confined to the upper few hundred meters of the water column. The link to ENSO as the cause of the variation in mean sea level is supported by high correlation with global mean SST anomalies and an EOF decomposition of the sea level and SST maps. This large change in global mean sea level and SST requires the ocean to gain heat during the ENSO event. One possible mechanism causing the ocean to retain heat is the large increase in global mean PWV during the ENSO event, which in turn caused the OLR to decrease. However, the relationship between ehanges in sea level, SST, and PWV during ENSO need more study before the phenomena can be completely understood. Perhaps most importantly, the presence of ENSO-scale variability in global mean sea level will require the collection of at least a decade of high accuracy altimeter data before the much smaller climate change signals can be observed, and thus the source of the $2.6 \mathrm{~mm} /$ year sea level rise observed over the six years of the T/P mission cannot currently be identified.

Acknowledgments. This investigation was supported by a NASA TOPEX/POSEIDON Project Science Investigation. Victor Zlotnicki participated in several useful discussions concerning the variations in precipitable water vapor.

\section{References}

Carton, J.A., B.S. Giese, X. Cao, and L. Miller, Impact of altimeter, thermistor, and expendable bathythermograph data on retrospective analyses of the tropical Pacific Ocean, J. Geophys. Res., 10I (C6), $14,147-14,160,1996$

Chambers, D.P., J.C. Ries, C.K. Shum, and B.D. Tapley, On the use of tide gauges to determine altimeter drift, J. Geophys. Res., 103 (C6), $12,885-12,890,1998$

daSilva, A.M., C.C. Young, and S. Levitus, Atlas of Surface Marine Data 1994, Volume 1: Algorithms and Procedures, NOAA Atlas NESDIS, 6, 1994.

Fu, L.-L., E.J. Christensen, C.A. Yamarone, Jr., M. Lefebvre, Y Menard, M. Dorrer, and P. Escudier, TOPEX/POSEIDON mission overview, J. Geophys. Res., 99 (C12), 24,369-24,382, 1994.

Haines, B.J., and Y.E. Bar-Sever, Monitoring the TOPEX microwave radiometer with GPS: Stability of columnar water vapor measurements, Geophys. Res. Lett., 25 (19), 3563-3566, 1998.

Hayne, G.S., D.W. Hancock, and C.L. Purdy, TOPEX altimeter range stability estimates from calibration mode data, TOPEX/POSEIDON Research News, 3, 18-22, 1994.

Hendricks, J.R., R.R. Leben, G.H. Born, and C.J. Koblinsky, Empirical orthogonal function analysis of global TOPEX/POSEIDON altimeter data and implications for detection of global sea level rise, $J$. Geophys. Res., 101 (C6), 14,131-14,146, 1996.

Jackson, D.L., and G.L. Stephens, A study of SSM/I-derived columriar water vapor over the global oceans, J. Climate, 8, 2025-2038, 1995.

Kalnay, E., and 21 others, The NCEP/NCAR 40-year reanalysis project, Bull. Am. Met. Soc., 77, 437-471, 1996.

Keihm, S., V. Zlotnicki, C. Ruf, and B. Haines, TMR Drift and Scale Error Assessment, Draft Report, Jet Propulsion Laboratory, 1-11, 1998

Leuliette, E.W., and J.M. Wahr, Coupled pattern analysis of sea surface temperature and TOPEX/POSEIDON sea surface height, $J$. Phys. Oceanography, 29 (April), 599-611, 1999.

Minster, J.-F., C. Brossier, and P. Rogel, Variation of the mean sea level from TOPEX/POSEIDON data, J. Geophys. Res., 100 (C12), 25,153-25,162, 1995

Minster, J.F., A. Cazenave, Y.V. Serafini, F. Mercier, M.C. Gennero, and P. Rogel, Annual cycle in mean sea level from Topex-Poseidon and ERS-1: Inference on the global hydrological cycle, Global and Planetary Change, 20, 57-66, 1999.

Mitchum, G.T., Comparison of TOPEX sea surface heights and tide gauge sea levels, J. Geophys. Res., 99 (C12), 24,541-24,554, 1994.

Mitchum, G.T., Monitoring the stability of satellite altimeters with tide gatiges, J. Atmos. and Oceanic Tech., 15 (June), 721-730, 1998.

Nerem, R.S., Global mean sea level variations from TOPEX/POSEIDON altimeter data, Science, 268, 708-710, 1995a.

Nerem, R.S., Measuring global mean sea level variations using TOPEX/POSEIDON altimeter data, J. Geophys. Res., 100 (C12), $25,135-25,152,1995 \mathrm{~b}$.

Nerem, R.S., Global mean sea level change: Correction, Science, 275 (February 21), 1053, 1997

Pacanowski, R., MOM 2 Documentation, User's Guide and Reference Manual, GFDL Ocean Technical Report, 1995.

Peterson, R.G., and W.B. White, Slow oceanic teleconnections linking the Antarctic Circumpolar Wave with the tropical El Nino-Southern Oscillation, J. Geophy. Res., 103 (C11), 24573-24583, 1998.

Reynolds, R.W., and T.S. Smith, Improved global sea surface temperature analysis, J. Climate, 7, 929-948, 1994.

Smith, T.M., R.W. Reynolds, R.E. Livezey, and D.C. Stokes, Reconstruction of historical sea surface temperatures using empirical orthogonal functions, $J$. Climate, 9 (June), 1403-1420, 1996.

Tapley, B.D., D.P Chambers, C.K. Shum, R.J. Eanes, J.C. Ries, and R.H. Stewart, Accuracy assessment of the large-scale dynamic ocean topography from TOPEX/POSEIDON altimetry, J. Geophys. Res., 99 (CI2), 24,605-24,618, 1994.

Wong, T., B.R. Barkstrom, G.G. Gibson, and S. Weckmann, Observations of the radiative impacts of ENSO events using data from ERBE and CERES, Eos Trans., 79 (45), F147, 1998.

D. P. Chambers, E. W. Leuliette, and R. S. Nerem, Center for Space Research, The University of Texas at Austin, Austin, TX, 78712. (email: nerem@csr.utexas.edu)

G. T. Mitchum, Department of Marine Science, University of South Florida, 140 Seventh Ave. South, St. Petersburg, FL, 33701 (e-mail: mitchum@seas.marine.usf.edu).

B. S. Giese, Department of Oceanography, Texas A\&M University, College Station, TX, 77843 (e-mail: giese@sweeney.tamu.edu).

(Received February 26, 1999; revised May 26, 1999;

accepted July 30,1999 ) 